\title{
Estudo de Caso: Impacto dos Custos Logísticos em Agroindústria de Polpas de Frutas no Município de Benjamin Constant - Amazonas
}

Case Study: Impact of Logistic Costs on Fruit Pulp Agroindustry in the Municipality of Benjamin Constant - Amazonas

Estudio de Caso: Impacto de los Costos Logísticos en Agroindustria de Pulpas de Frutas en el Municipio de Benjamin Constant - Amazonas

Kleber Bittencourt Oliveira² kleberbo@yahoo.com.br http://lattes.cnpq.br/3202890124751363 https://orcid.org/0000-0002-5998-5129 
Estudo de Caso: Impacto dos Custos Logísticos em Agroindústria de Polpas de Frutas no Município de Benjamin Constant - Amazonas

\title{
Resumo
}

A implantação de negócios de qualquer segmento na região amazônica é uma tarefa desafiadora, devido principalmente aos altos custos logísticos, pois as características fisiográficas desafiam a execução do transporte, sobretudo pelas grandes distâncias a serem percorridas aliadas às deficiências existentes nos diversos modais. Por isso mesmo, esta pesquisa buscou analisar o impacto dos custos logísticos nos processos industriais realizados por uma agroindústria de polpas de frutas instalada no município de Benjamin Constant, Amazonas. Para tanto, realizou-se uma pesquisa do tipo exploratória e explicativa, na forma combinada (qualitativa e quantitativa), tendo como método de pesquisa um Estudo de Caso, utilizando de entrevistas, observações e informações de arquivo (pesquisa documental) para coleta de dados. Ao final, identificou-se as principais potencialidades e ameaças logísticas à implantação, consolidação e manutenção da fábrica estudada, como também apresenta-se um plano para aperfeiçoamento da Gestão da Cadeia de Suprimentos, visando a redução dos custos logísticos, e, consequentemente, a otimização dos processos de fabricação e distribuição. Com isto, acredita-se estar contribuindo para o fortalecendo da indústria local, aumentando oferta de emprego e melhoria de renda à população do município, e também, justificando a necessidade de investimento público no aprimoramento da infraestrutura logística da região amazônica.

Palavras chave: Custos Logísticos. Cadeia de Abastecimento. Agronegócios. Polpa de Fruta.

\section{Case Study: Impact of Logistic Costs on Fruit Pulp Agroindustry in the Municipality of Benjamin Constant - Amazonas}

\begin{abstract}
The implantation of businesses of any segment in the Amazon region is a challenging task, mainly due to the high logistic costs, because the physiographic characteristics challenge the execution of the transport, especially for the great distances to be traveled allied to the deficiencies existing in the various modalities. For this reason, this research aimed to analyze the impact of logistics costs on industrial processes carried out by a fruit pulp agro-industry located in Benjamin Constant, Amazonas. For this, an exploratory and explanatory research was carried out, in the combined form (qualitative and quantitative), using as a research method a Case Study, using interviews, observations and archival information (documentary research) to collect data. . At the end, the main logistical potentials and threats to the implementation, consolidation and maintenance of the studied plant were identified, as well as a plan for the improvement of Supply Chain Management, aiming at the reduction of logistics costs, and consequently, the optimization of manufacturing and distribution processes. With this, it is believed to be contributing to the strengthening of the local industry, increasing job offer and income improvement to the population of the municipality, and also justifying the need for public investment in improving the logistics infrastructure of the Amazon region.
\end{abstract}

Keywords: Logistic costs. Supply Chain. Agribusiness. Fruit Pulp.

Estudio de Caso: Impacto de los Costos Logísticos en Agroindustria de Pulpas de Frutas en el Municipio de Benjamin Constant - Amazonas

\section{Resumen}


Estudo de Caso: Impacto dos Custos Logísticos em Agroindústria de Polpas de Frutas no Município de Benjamin Constant - Amazonas

La implantación de negocios de cualquier segmento en la región amazónica es una tarea desafiante, principalmente debido a los altos costos logísticos, debido a que las características fisiográficas desafían la ejecución del transporte, especialmente para las grandes distancias a recorrer aliadas a las deficiencias existentes en las diversas modalidades. Por esta razón, esta investigación tuvo como objetivo analizar el impacto de los costos logísticos en los procesos industriales llevados a cabo por una agroindustria de pulpa de fruta ubicada en Benjamin Constant, Amazonas. Para esto, se llevó a cabo una investigación exploratoria y explicativa, en forma combinada (cualitativa y cuantitativa), utilizando como método de investigación un Estudio de caso, utilizando entrevistas, observaciones e información de archivo (investigación documental) para recopilar datos. . Al final, se identificaron los principales potenciales logísticos y las amenazas a la implementación, consolidación y mantenimiento de la planta estudiada, así como un plan para la mejora de la gestión de la cadena de suministro, con el objetivo de reducir los costos logísticos y, en consecuencia, optimización de procesos de fabricación y distribución. Con esto, se cree que está contribuyendo al fortalecimiento de la industria local, aumentando la oferta de trabajo y la mejora de los ingresos para la población del municipio, y también justificando la necesidad de inversión pública para mejorar la infraestructura logística de la región amazónica.

Palabras clave: Costes Logísticos. Cadena de Suministro. Agroindustria. Pulpa de Fruta. 
Estudo de Caso: Impacto dos Custos Logísticos em Agroindústria de Polpas de Frutas no Município de Benjamin Constant - Amazonas

\section{INTRODUÇÃO}

No cenário de intensas transformações impulsionadas pelos avanços tecnológicos, as integrações comerciais e financeiras e a acirrada concorrência mundial, a logística empresarial vem se tornando uma das áreas funcionais para o sucesso das organizações. Este reconhecimento decorre do potencial da função logística no desenvolvimento de estratégias que possibilitem o alcance da eficácia organizacional e manutenção de vantagens competitivas adquiridas (Souza, M. A. et al., 2013).

Sabe-se que os custos logísticos, principalmente aqueles relativos aos meios de transportes, representam uma parcela expressiva no custo total das mercadorias, considerando que é através dos seus processos que os insumos chegam até as fábricas e/ou os produtos são distribuídos aos consumidores finais (Sakai, 2011). Consequentemente, a redução dos custos logísticos proporciona aumento da lucratividade das empresas, apresentando-se como uma alternativa eficiente de adaptar-se as instabilidades mercadológicas do atual cenário econômico (Souza, Schnorr \& Ferreira, 2013).

Particularmente na Região Amazônica, as características fisiográficas desafiam a execução do transporte, sobretudo pelas grandes distâncias a serem percorridas aliadas às deficiências existentes nos diversos modais, onerando, sobremaneira, sua função logística (Bringel apud Passos, 2013). Nesse contexto Souza, P. A. R., et al. (2011) salienta que o problema da Região Amazônica não é apenas logística, mas também a falta de infraestrutura para o atendimento da região, passando também pelo âmbito governamental. Ainda segundo o autor, falta para a região investimentos para manutenção e conclusão de rodovias, como também a elaboração de um plano para a utilização do potencial hídrico amazônico, o que torna ainda mais evidente que esta região sofre grandes precariedades no que tange a essa temática.

Tem-se na utilização de técnicas como a Gestão da Cadeia de Abastecimento, ou mesmo a Logística Integrada, como alternativas para proporcionar aumento da produtividade e, consequentemente, contribuir significativamente para a redução de custos, o que também, permite identificar-se novas formas de se agregar valor aos produtos.

Desta forma, o objetivo principal deste trabalho foi analisar os impactos dos custos logísticos em uma fábrica de polpas de frutas, localizada no município de Benjamin Constant, Estado do Amazonas. Onde identificou-se as principais "potencialidades" e "ameaças" logísticas que influenciam na implantação, consolidação e manutenção, bem como contribuir para o aperfeiçoamento da Gestão da Cadeia de Abastecimento desta fábrica, visando à redução dos custos logísticos e consequentemente, a otimização dos seus processos de fabricação e distribuição.

\section{LOGÍSTICA EMPRESARIAL}

Dentre os vários conceitos de Logística apontados por diversos autores pode-se dizer em termos práticos que é talvez a área primordial no meio empresarial, pois tem que lidar com equipamentos e informações para a execução de todas as atividades que fazem com que a empresa chegue ao topo dos negócios.

Para tanto, Silva (2012) elucida que a logística é o processo de planejamento, implementação e controle eficiente e eficaz do fluxo e armazenagem de mercadorias, serviços e informações 
Estudo de Caso: Impacto dos Custos Logísticos em Agroindústria de Polpas de Frutas no Município de Benjamin Constant - Amazonas

relacionadas desde o ponto de origem até o ponto de consumo, com objetivo de atender as necessidades do cliente.

Segundo Ballou (2010) a logística empresarial visa estudar como a administração pode prover um melhor nível de rentabilidade nos serviços de distribuição aos clientes e consumidores, através de planejamento, organização e controle efetivo para as atividades de movimentação e armazenagem que visam facilitar o fluxo de produtos.

Com o advento da globalização, devido à constante quebra de barreiras comerciais, o mercado se tornou altamente competitivo, exigindo a busca incessante da excelência e da qualidade dos produtos e serviços para atender ao cliente de forma mais satisfatória. É nesse contexto que o complexo e extenso ramo da logística é desafiado em toda a sua extensão, particularmente quanto à gestão do transporte, por ser este o responsável pela movimentação de mercadorias e estar sendo constantemente influenciado pelas tecnologias emergentes (Vargas apud Vieira \& Vieira, 2014).

Considerando a historicidade da atividade da logística e as mudanças que mesma sofreu no decorrer destes anos é fundamental destacar sua evolução. Ballou (2012) promove o agrupamento da evolução histórica da logística empresarial em três momentos, evidenciando as situações em que os papeis das atividades de uma organização não eram bem definidos, o crescimento das práticas logísticas e pôr fim a sua aceitação em função de benefícios adquiridos, como mostra a Tabela 1.

Tabela 1.

Evolução Histórica da Logística Empresarial.

\begin{tabular}{cl}
\hline Era & \multicolumn{1}{c}{ Descrição } \\
\hline $\begin{array}{c}\text { Até 1950 } \\
\text { Os anos adormecidos }\end{array}$ & $\begin{array}{l}\text { Não existia uma divisão bem definida sobre as atividades } \\
\text { chave, ou seja, havia um conflito de interesses e } \\
\text { responsabilidades entre os setores de produção, finanças e } \\
\text { marketing para as atividades logísticas. }\end{array}$ \\
$\begin{array}{c}\text { Este período marca a era da expansão da prática da } \\
1950-1970\end{array}$ & $\begin{array}{l}\text { logística empresarial, pois estava vivenciando um momento } \\
\text { adequando para a implantação de novidades. }\end{array}$ \\
Operíodo de desenvolvimento & $\begin{array}{l}\text { Este período desencadeou a crescente aceitação da } \\
\text { logística, pois algumas empresas, por sua vez, já estavam } \\
\text { conseguindo obter benefícios em função do seu uso. }\end{array}$ \\
\hline
\end{tabular}

Nota. Adaptado de Ballou (2012).

Certamente as definições acima promovem o entendimento sobre o conceito, historicidade e relevância da logística empresarial. Esse conjunto axiológico passa a ser lido em função da realidade aonde não há dúvidas sobre a importância da logística no meio empresarial. Mesmo assim, é notória a falta de infraestrutura que a região do Amazonas oferece neste quesito, principalmente naqueles municípios mais longínquos da capital, seja por desassistência estatal, seja por inoperância empresarial. De acordo com Nogueira \& Machado (2004) a grande problemática encontrada nessa questão molda-se na precariedade de equipamentos, estradas, escassez de mão de obra especializada e falta de políticas públicas eficientes que ajudem a melhorar esse atual cenário. 
Estudo de Caso: Impacto dos Custos Logísticos em Agroindústria de Polpas de Frutas no Município de Benjamin Constant - Amazonas

\subsection{Custos Logísticos}

Ao discorrer sobre os custos logísticos devemos entender que tais correntes não se resumem especificamente ao transporte, apesar deste causar maior impacto no que se refere a desenvolvimento das pequenas e grandes empresas na atualidade. Apesar disso existem vários custos que se podem relacionar nesse rol. Dentre esses pode-se destacar o custo de transporte, custo de armazenagem e custo de estoques.

\subsubsection{Custo de transportes}

Nos dizeres de Guereschi (2012) a logística de transporte tem como função básica, transportar produtos ou bens, dando acesso à sociedade a adquirir um produto ou serviço que não esteja ao seu alcance, ou o estariam apenas a um elevado preço. Têm, assim, como função econômica de promover a integração entre sociedades que produzem bens diferentes entre si.

É perceptível que para grande parte das empresas, o transporte é a atividade logística mais importante porque se refere aos métodos para movimentação de produtos. Segundo Gutierrez apud Ferreira e Alves (2016) o transporte consome 30\% dos custos logísticos.

Em consonância com tal posicionamento Alves apud Kussano (2010) diz que o custo de transporte é influenciado pelos seguintes fatores:

- Distância: é o que tem maior influência no custo. O crescimento da curva de custo de frete diminui gradualmente com a distância;

- Volume: segue o princípio da economia de escala.

- Densidade: incorpora considerações de peso a ser transportado e espaço a ser ocupado. Regra geral: aumenta-se a densidade do produto para melhor aproveitamento da capacidade do veículo. Produtos a granel racionalizam a ocupação. Balancear com custos de sistemas de descarga para minimizar o custo total;

- Estiva: refere-se às dimensões e formas do produto, que possam afetar a utilização do espaço do veículo;

- Manuseio: equipamentos especiais para manuseio aumentam o custo;

- Responsabilidade: considera características do produto a ser transportado: suscetibilidade a avarias, roubos, perfectibilidade e seguro da carga;

- Mercado: existência de cargas nas rotas de retorno e sazonalidade de produtos agrícolas influencia o custo do frete na região.

\subsubsection{Custo de armazenagem}

Na concepção de Kussano (2010) a armazenagem tem como objetivo o estabelecimento do fluxo de movimentação dos materiais/produtos e suas decisões estão relacionadas às seguintes questões: áreas, condições e equipamentos e métodos operativos; inspeção e devolução de materiais; rotas de movimentação e manuseio; tempo de ciclo e ativos logísticos envolvidos.

De acordo com Faria e Costa (2007) há vários fatores que influenciam na determinação dos custos de armazenagem, tais como:

- Características de recebimento: contemplando volumes por grupo de produto, modo de transporte, características da carga, etc.;

- Características de acondicionamento (estocagem - quantidade por pallet, empilhamento de pallet, temperatura requerida, etc.); 
Estudo de Caso: Impacto dos Custos Logísticos em Agroindústria de Polpas de Frutas no Município de Benjamin Constant - Amazonas

- Características de seleção de pedido ou embarque: volume por grupo de produto, quantidade de lote de pedido, modo de transporte, taxa de atendimento de pedido e tempo de atendimento;

- Necessidades de etiquetagem;

- Características de reembalagem (bens danificados e especiais);

- Necessidade de mão-de-obra direta e de equipamentos;

- Necessidade de recursos indiretos (supervisão, manutenção de equipamentos, limpeza, segurança, suprimento, etc.).

\subsubsection{Custo de estoques}

Embora existam pequenas empresas ágeis e competitivas no que se refere ao desempenho logístico, principalmente no que tange a estoque, muitas dessas costumam se incluir no grupo daquelas nas quais as atividades logísticas não estão integradas, é o caso de muitas empresas na cidade de Benjamin Constant - Amazonas. Para essas, algumas medidas administrativas simples podem contribuir para um aumento significativo do desempenho em termos de nível de serviço e custos logísticos, proporcionando aumento do valor líquido oferecido ao cliente e do valor agregado pelas empresas.

Para Slack et al. (2009), existem seis modalidades que remetem o custo de estoque:

1. Custo de colocação de pedido: toda vez que um pedido é colocado para reabastecer o estoque, é necessário transações que representam custo para a empresa.

2. Custos de desconto de preços: Muitos fornecedores oferecem descontos sobre o preço normal de compra para grandes quantidades, também podem impor custos extras para pequenos pedidos;

3. Custo de falta de estoque: Se errarmos a quantidades de pedido e ficarmos sem estoque, haverá custos incorridos por nós, pela falha no fornecimento os nossos consumidores. Se os consumidores forem externos, poderão trocar de fornecedor; se internos, a falta de estoque pode levar a tempo ocioso no processo seguinte, ineficiências e, eventualmente, outra vez consumidores externos insatisfeitos;

4. Custo de capital de giro: quando colocarmos um pedido de reabastecimento, para os nossos fornecedores, eles vão demandar pagamento de seus produtos. Quando fornecemos para nossos próprios clientes, vamos, por nossa vez demandar recebimentos. Por, todavia, haverá provavelmente um intervalo de tempo entre pagar os fornecedores e receber de nossos clientes. Durante esse tempo, temos que ter fundos para manter os estoques. Os custos associados são os juros que pagamos ao banco por empréstimos, ou custos de oportunidade de não investirmos em outros lugares;

5. Custo de armazenagem: São os custos associados a armazenagem física dos bens, locação, iluminação e climatização do armazém, juntamente com seguro;

6. Custos de obsolescência: Quando escolhemos uma política de pedidos que envolvem pedidos de quantidades muitos grandes, o que significará que os itens estocados permanecerão por longos tempos armazenados, incorre no risco de que esses itens possam se tornar obsoletos, ou deteriorar-se, juntamente com a perda por danificação.

\section{METODOLOGIA}

\subsection{Método de Pesquisa}

O método de pesquisa utilizado foi o estudo de caso, que permitiu uma análise em profundidade do objeto de estudo preocupando-se com questões do tipo "como" e "por que" 
Estudo de Caso: Impacto dos Custos Logísticos em Agroindústria de Polpas de Frutas no Município de Benjamin Constant - Amazonas

do problema estudado (Acevedo \& Nohara, 2007). Segundo Yin (2005) o estudo de caso é "uma inquirição empírica que investiga um fenômeno contemporâneo dentro de um contexto da vida real, quando a fronteira entre o fenômeno e o contexto não é claramente evidente e onde múltiplas fontes de evidência são utilizadas".

\subsection{Tipo de Pesquisa}

Este trabalho envolveu dois tipos de pesquisa: exploratória e explicativa. A pesquisa exploratória proporciona maior compreensão do fenômeno que está sendo investigado, permitindo que delineemos de forma mais precisa o problema (Acevedo \& Nohara, 2007). Já pesquisa explicativa proporciona a identificação dos fatores que determinam ou contribuem para a ocorrência dos fenômenos pesquisados, requerendo do uso do método experimental, principalmente (Mello \& Turrioni, 2012).

\subsection{Natureza da Pesquisa}

A natureza desta pesquisa foi qualitativa e quantitativa, ou seja, na forma combinada. Esta forma de pesquisa permite que o pesquisador combine os aspectos das pesquisas qualitativas e quantitativas em todos ou em algumas das etapas do processo de pesquisa (Mello \& Turrioni, 2012).

\subsection{Técnicas de Coleta de Dados}

Nesta pesquisa foram utilizadas entrevistas, observações e informações de arquivo (pesquisa documental). As entrevistas realizadas foram do tipo não estruturada, onde o pesquisador tem liberdade para desenvolver cada situação em qualquer direção que considere adequada, permitindo ao entrevistado decidir-se pela forma de construir a resposta (Laville \& Dione, 1999).

Nas observações obteve-se as informações necessárias ao desenvolvimento da pesquisa utilizando-se dos sentidos para obtenção de determinados aspectos da realidade, não consistindo apenas em ver e ouvir, mas também em examinar fatos ou fenômenos que se desejam estudar. A técnica de observação garante a apreensão de comportamentos e acontecimentos no momento em que eles se produzem, sem a interferência de documentos ou pessoas. Permite ainda, ao pesquisador posicionar-se dentro do ambiente organizacional de forma que ele possa compreender a complexidade dos acontecimentos, ao mesmo tempo em que lhe permite uma interlocução mais competente (Zanelli, 2002).

Também foram adotadas como técnicas de manuseio as informações de arquivo (pesquisa documental) que abrange as informações financeiras e operacionais da organização, que possam ser tabuladas e mensuradas em dados quantitativos para análise, bem como uma intensiva revisão bibliográfica, permitindo ao pesquisador realizar comparações com que foi publicado por estudiosos e pesquisadores credenciados (Mello \& Turrioni, 2012).

\section{ESTUDO DE CASO}

\subsection{Identificação do Local Estudado}

Este trabalho estudou uma fábrica de polpas de frutas, identificada neste estudo pelo nome fictício "Polpas da Amazônia", instalada no município de Benjamin Constant, estado do 
Estudo de Caso: Impacto dos Custos Logísticos em Agroindústria de Polpas de Frutas no Município de Benjamin Constant - Amazonas

Amazonas, região que se apresenta com uma infraestrutura logística deficitária. O principal desafio dos empreendedores é garantir o abastecimento do principal mercado consumidor, a cidade de Manaus, distante 1.119 Km do município como mostra a Figura 1.

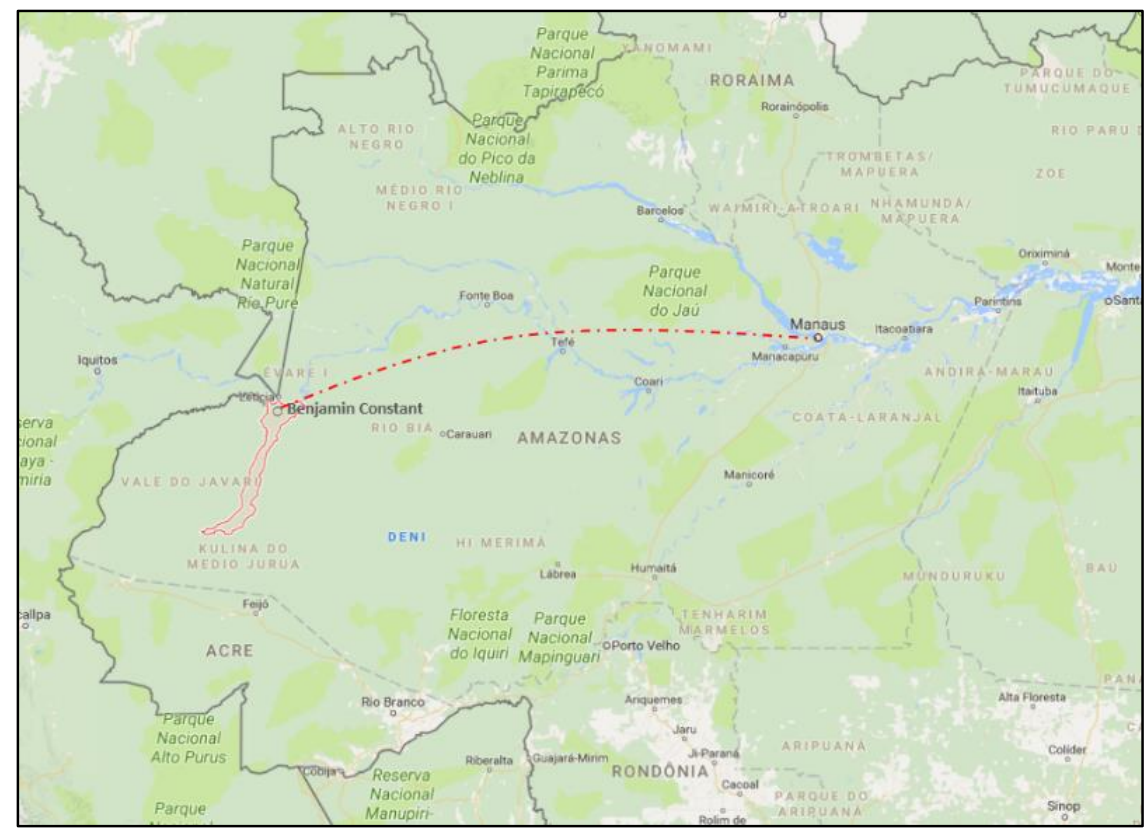

Figura 1. Distância entre os municípios de Benjamin Constant e Manaus. Fonte: Adaptado do Google Earth (2016).

A fábrica teve início às suas atividades em 2010 processando polpas de abacaxi, açaí, buruti, camu-camu e cupuaçu. No período de 2013 a 2015 a "Polpas da Amazônia" produziu mais de 300 toneladas de polpas de frutas, destaque para a polpa de açaí como a matéria-prima com maior representatividade conforme mostra a Figura 2.

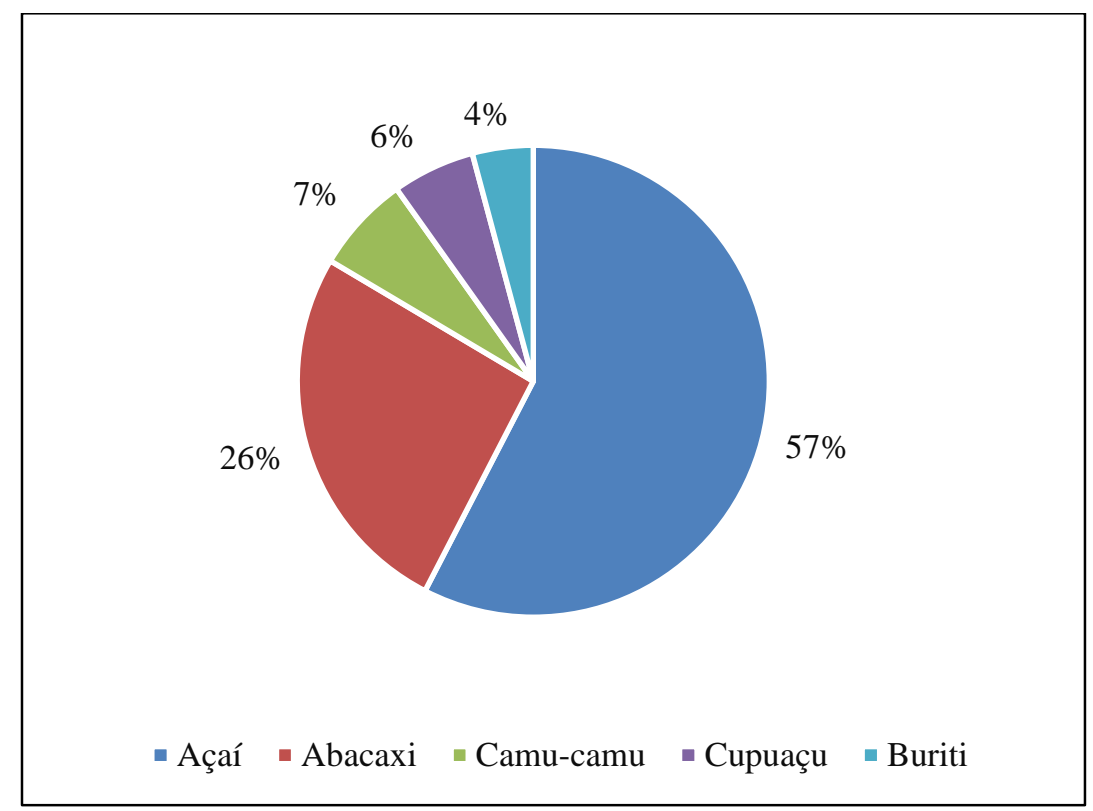

Figura 2. Matérias-primas processadas pela "Polpas da Amazônia" 2013 a 2015.

Fonte: Autor (2016).

UFAMBR, Manaus, v. 1, n.2, art. 3, pp. 42-66, julho-dezembro, 2019 http://www.periodicos.ufam.edu.br/ufambr 
Estudo de Caso: Impacto dos Custos Logísticos em Agroindústria de Polpas de Frutas no Município de Benjamin Constant - Amazonas

\subsection{Cadeia de Suprimentos}

Na concepção de Christopher (2009), a cadeia de suprimento é uma rede de organizações envolvidas por meio dos vínculos a montantes e a jusante, nos diferentes processos e atividades que produzem valor na forma de produtos e serviços destinados ao consumidor final. $\mathrm{O}$ autor também salienta que gerenciamento da cadeia de suprimento não é integração vertical.

Por sua vez, sobre a temática, Ballou (2006) define a cadeia de suprimentos como sendo um conjunto de atividades funcionais (transportes, controle de estoques, etc.) que se repetem inúmeras vezes ao longo do canal pelo qual matérias-primas vão sendo convertidas em produtos acabados, aos quais se agrega valor ao consumidor.

A empresa "Polpas da Amazônia" apresenta uma Cadeia de Suprimentos dividas em fases de Fornecimento, Produção e Distribuição como mostra a Figura 3. A análise da fase de Produção não foi autorizada pela empresa "Polpas da Amazônia", desta forma, este trabalho delimitou-se ao estudo das fases de Fornecimento e Distribuição.

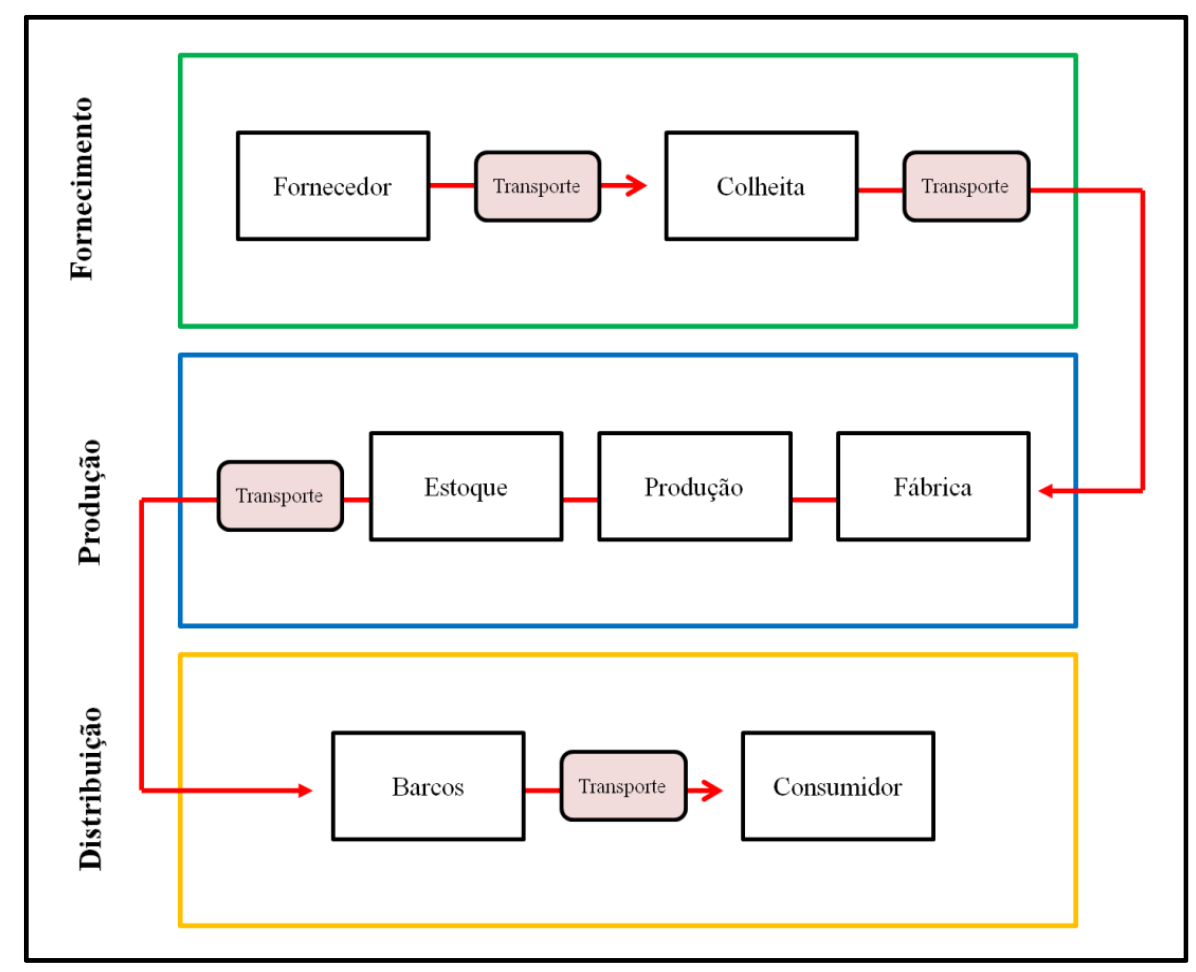

Figura 3. Cadeia de Suprimentos da fábrica "Polpas da Amazônia" Fonte: Autor (2016).

\subsubsection{Fornecedores}

Sendo a fábrica pioneira no ramo da agroindústria no município de Benjamin Constant, Amazonas, logo se deparou com a baixa oferta de matéria-prima, pois sem um mercado em potencial, não havia porque os fornecedores colher/produzir grandes quantidades de frutas, pois a demanda era basicamente o comércio local. 
Estudo de Caso: Impacto dos Custos Logísticos em Agroindústria de Polpas de Frutas no Município de Benjamin Constant - Amazonas

O processo de pagamento entre extrativista e produção (indústria) é realizado em dinheiro e crédito. Com frequência, o processo de pagamento de crédito entre atores e indústrias foi conduzido após o processo de venda (vendido). Apenas alguns deles conduzidos em pagamento de crédito ou pagamento estendido. Todo o processo de pagamento tende a "confiar" no conceito como um compromisso entre eles para construir uma relação de longo prazo entre os atores no mecanismo da cadeia de suprimentos. De acordo com Grim et al., (2014) a confiança entre os atores na cadeia de suprimentos deve ser levantada para manter uma relação de longo prazo no sistema logístico.

Esta relação de confiança possibilitou a fábrica realizar um cadastro dos seus fornecedores, organizando-os por sua localidade (Comunidade, Estrada, Rodovia, Rio, Igarapé, etc.), que além de garantir a rastreabilidade da matéria-prima, possibilita ainda que se aprimore o processo de colheita e transporte destas frutas, atendendo às exigências mercadológicas e legais, e aprimorando as propriedades organolépticas do produto final.

Segundo Jack et al., (2007) diz que as agroindústrias trabalham esses fatores no sistema de contrato para manter a relação de longo prazo de atividades de aquisição de matéria-prima, uma vez que garante o volume certo, quantidade certa, qualidade certa, no lugar certo e na hora certa. Entretanto, o sistema de contrato para a fábrica estudada mostra-se ineficiente, pela irregularidade no fornecimento de matéria-prima, principalmente em fatores como quantidades e remessas.

\subsubsection{Consumidores}

A comercialização dos produtos da Agroindústria no comércio local é dificultada principalmente pela forte concorrência de vendedores ambulantes. Atualmente o quilo de polpa de açaí que é produzido na fábrica tem valor 57\% superior daquele comercializado pelos ambulantes. E, ainda tem-se uma questão cultural dos consumidores quanto à preferência pelos ditos "produtos frescos", que seriam aqueles que não passaram por processos de industrialização e/ou conservação.

Nesse sentido, Karsaklian (2000) afirma que por mais que se busque compreender o comportamento do consumidor, é difícil saber quais comportamentos ele vai ter em relação aos fatos que venham ocorrer durante a vida. De qualquer modo, sabemos que eles são influenciados por necessidades e diversas variáveis. Talvez isso justifique a busca por outros mercados consumidores, até mesmo porque atualmente toda a produção da "Polpas da Amazônia" é comercializada na cidade de Manaus - Amazonas.

\subsubsection{Transporte e distribuição}

Na Amazônia muitas das cidades estão inseparavelmente ligadas aos rios, nas margens das quais foram fundadas. Até mesmo por isso, a hidrografia permitiu o intercâmbio de bens entre as comunidades ao longo dos anos, e ao mesmo tempo desempenhou um papel extremamente importante para o desenvolvimento econômico da região.

Para a logística empresarial, verificou-se a importância do modal hidroviário para os processos industriais da Agroindústria quando analisamos especificamente o transporte do açaí, onde a fruta que chega à fábrica vem de uma área de aproximadamente 2,5 milhões de $\mathrm{km}^{2}$, como mostra a Figura 4, compreendendo desde o Rio Quixito, a Oeste, até à Comunidade de Prosperidade, ao Leste; do município de Tabatinga, ao Norte, até a zona rural 
Estudo de Caso: Impacto dos Custos Logísticos em Agroindústria de Polpas de Frutas no Município de Benjamin Constant - Amazonas

do município de Benjamin Constant, ao Sul, ou seja, a colheita do açaí numa área com essas dimensões somente é possível pelo potencial hidroviário oferecido pela região.

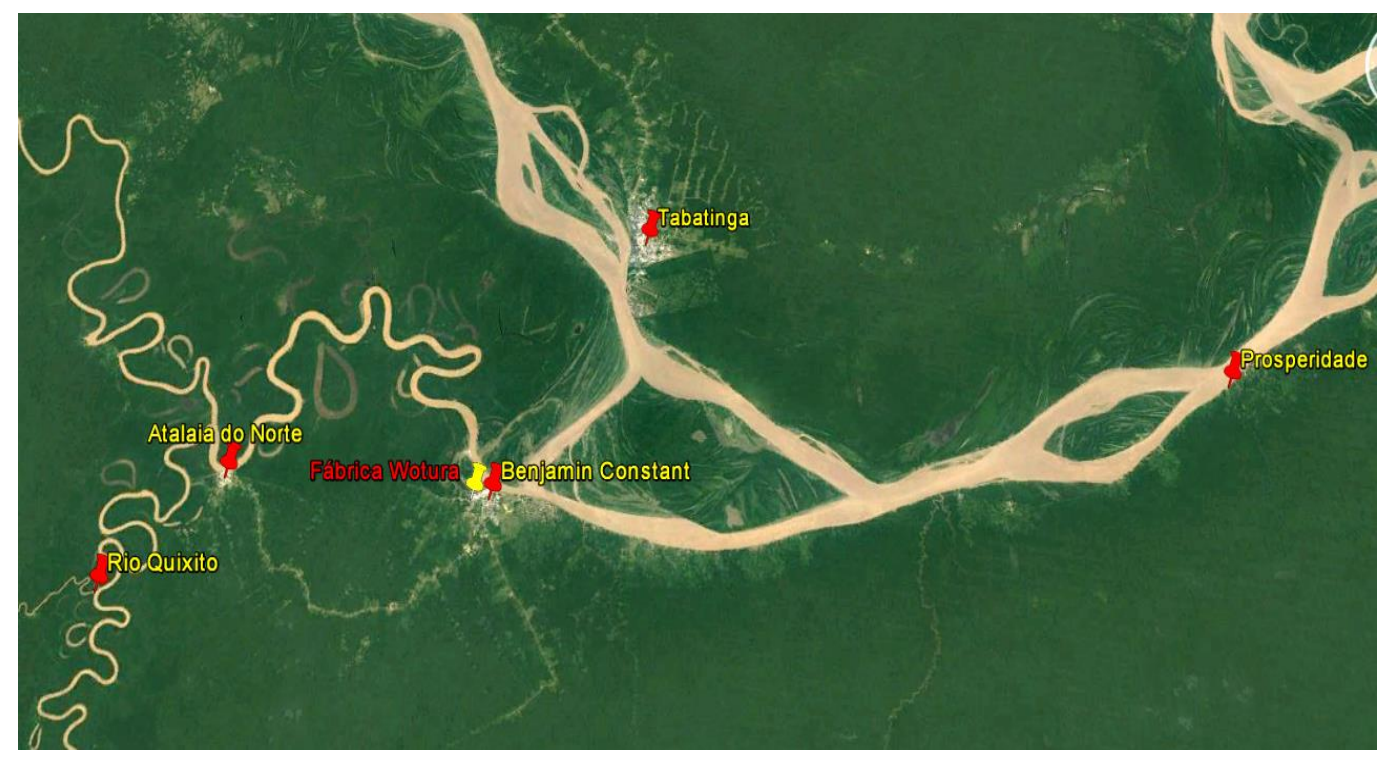

Figura 4. Área de colheita de açaí. Fonte: Adaptado do Google Earth (2016).

Este potencial fica evidente quando se verifica que $86 \%$ da distância percorrida pela matériaprima é realizada pelos rios, lagos e igarapés como mostra a Tabela 2. Isso confronta os padrões nacionais, onde $60 \%$ das cargas são transportadas pelo modal rodoviário, e as hidrovias são responsáveis por apenas 7\% (Oliva, 2008).

Tabela 2.

Modais e Distâncias Utilizadas no Transporte de Matéria-Prima.

\begin{tabular}{ccc}
\hline Hidroviário & Rodoviário & Total \\
\hline $1.020,90 \mathrm{Km}$ & $161,60 \mathrm{Km}$ & $1.182,50 \mathrm{Km}$ \\
$86 \%$ & $14 \%$ & $100 \%$ \\
\hline
\end{tabular}

Nota. Autor (2016).

O papel fundamental que as hidrovias exercessem no processo logístico fica ainda mais evidente durante o fenômeno amazônico da cheia dos rios, que influencia diretamente na colheita do açaí. Alguns pontos de colheita dentro da floresta somente são possíveis se os canais que dão acesso estejam navegáveis no período de safra da fruta. A Figura 5 mostra a formação dos canais na floresta amazônica durante o período de cheia dos rios. 
Estudo de Caso: Impacto dos Custos Logísticos em Agroindústria de Polpas de Frutas no Município de Benjamin Constant - Amazonas

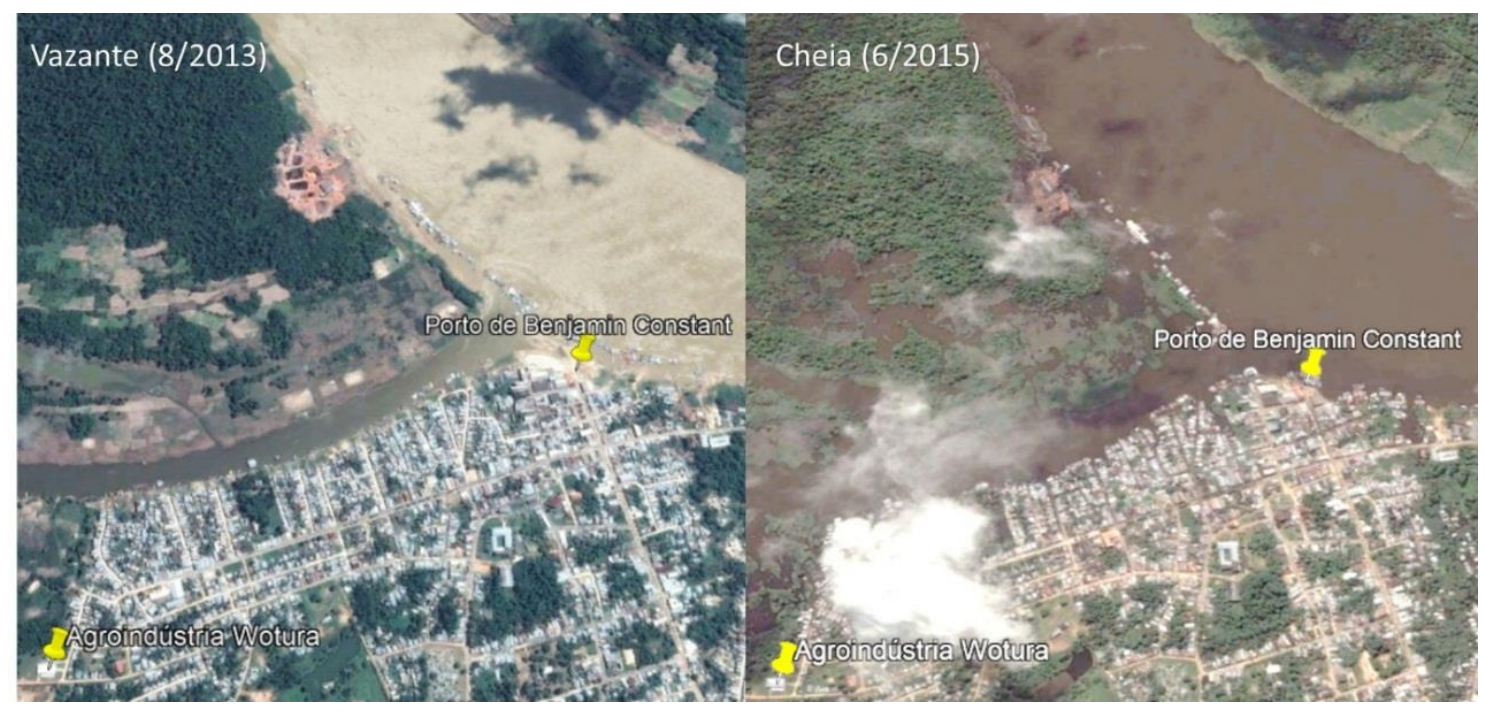

Figura 5. Comparação entre períodos da vazante e cheia do Rio Javari. Fonte: Adaptado do Google Earth (2016).

A distribuição das polpas de frutas também é realizada em sua maior parte pelo modal hidroviário, representando 99,8\% do percurso total como mostra a Tabela 3.

Tabela 3.

Modais e Distâncias Utilizadas na Distribuição de Produtos.

\begin{tabular}{ccc}
\hline Hidroviário & Rodoviário & Total \\
\hline $1.575 \mathrm{Km}$ & $3,7 \mathrm{Km}$ & $1.182,50 \mathrm{Km}$ \\
$99,8 \%$ & $0,2 \%$ & $100 \%$ \\
\hline
\end{tabular}

Nota: Autor (2016).

Apesar da carência de modais de transporte na região, sabe-se que as excelentes credenciais ambientais, os elevados padrões de segurança para as expedições, a grande capacidade de carga embarcações e boa rentabilidade são algumas das características excepcionais do modal hidroviário, que favorecem sua escolha. Contudo, a baixa disponibilidade desse tipo de serviço pode limitar a capacidade de atendimento de consumo.

Importante frisar que o modal rodoviário apresenta-se como gargalo à produção, causando principalmente falhas no fornecimento da matéria-prima. Como Segre (2007) afirma, as fragilidades no modal rodoviário são representadas pelas condições precárias das rodovias, resultado de uma infraestrutura inadequada e deterioradas, além de um baixo nível de manutenção.

Desta forma, apesar do modal rodoviário ser um meio de transporte que oferece maior agilidade e disponibilidade, a precariedade das ruas, rodovias e estradas no município interfere principalmente no fornecimento de matéria-prima. Com pavimentação inexistente ou precária, e a safra do açaí coincidindo com o período de chuvas, os fornecedores nem sempre conseguem cumprir o prazo de entrega estabelecido pela fábrica.

\section{GESTÃO DE ESTOQUES}

A gestão de estoques constitui uma série de ações que permitem às organizações verificar se os estoques estão bem utilizados, localizados, manuseados e controlados (Martins \& Alt, 
Estudo de Caso: Impacto dos Custos Logísticos em Agroindústria de Polpas de Frutas no Município de Benjamin Constant - Amazonas

2009). Sabe-se que uma eficiente gestão de estoques garante maior disponibilidade dos produtos ao consumidor, obtendo-se uma vantagem competitiva em relação a acirrada concorrência dos mercados.

\subsection{Previsão de Estoques}

A previsão de estoques faz-se necessária na medida em que os processos de fornecimento e demanda não podem ser sincronizados, sejam por variabilidades naturais no processo ou mesmo por razões econômicas (Gianesi \& Biazzi, 2011). Até mesmo porque, os processos logísticos que envolvem a agroindústria são relativamente mais complexos uma vez que seus produtos têm características específicas a serem consideradas, tais como, o alto grau de perecibilidade (com utilização rigorosa da cadeia do frio, em muitos casos), sazonalidade e dispersão de produção agropecuária e diversas variáveis que afetam o comportamento do consumidor (Silva \& Batalha apud Silva \& Fischmann, 1999)

Neste caso, observou-se que a empresa "Polpas da Amazônia" vende tudo aquilo que produz, possibilitando manter estoques mínimos, reduzindo significativamente os custos logísticos. No entanto, esses estoques extremamente reduzidos são mais do que decisões administrativas, é uma consequência da falta de fornecimento de matéria-prima, pois o consumo mensal está abaixo de sua capacidade produtiva ( $\cong 90.000 \mathrm{Kg} / \mathrm{mês}$ ) como mostra a Figura 6, onde mesmo nos picos de produção tem-se uma diferença de pelos menos 60.000 quilos.

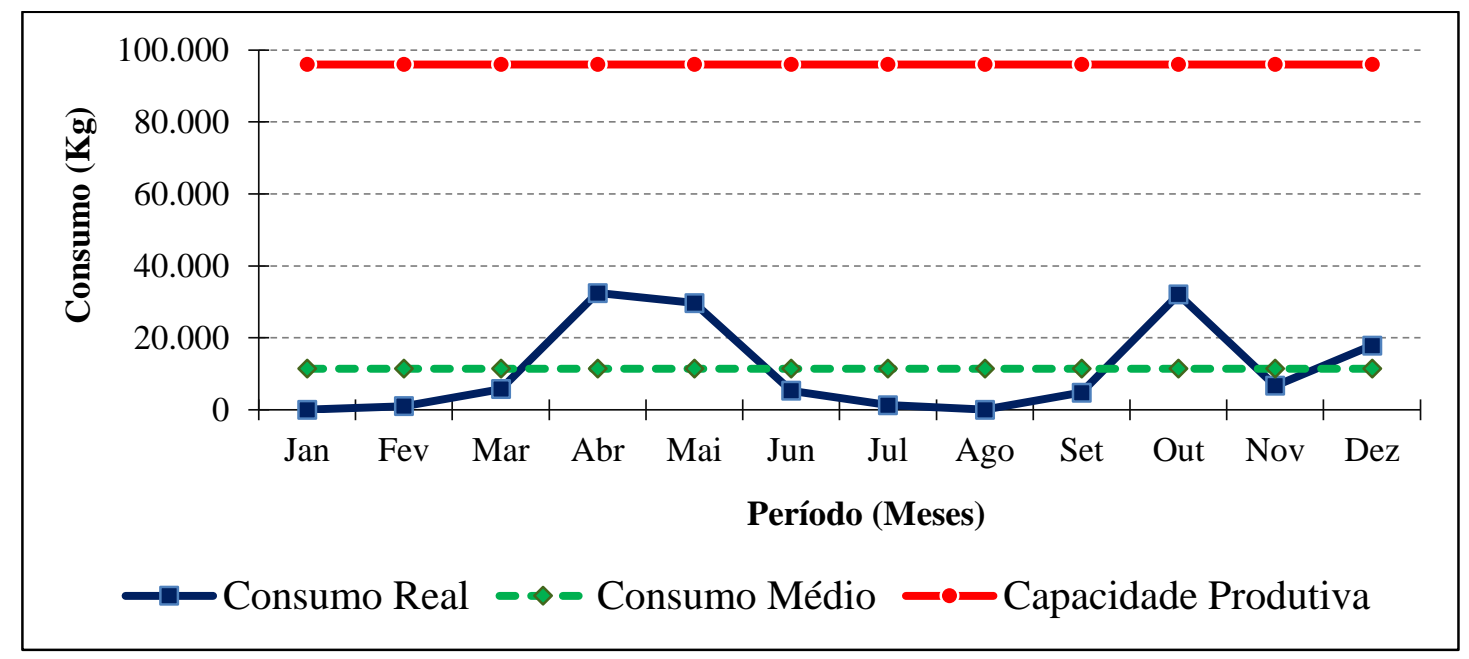

Figura 6. Evolução de Consumo Sazonal (ECS) da empresa "Polpas da Amazônia". Fonte: Autor (2016).

Para uma produção de $90.000 \mathrm{Kg} / \mathrm{mês}$ de polpas de frutas, a empresa precisará, no mínimo, de um fornecimento $180.000 \mathrm{Kg} / \mathrm{mês}$ de matéria-prima. Constata-se que a "Polpas da Amazônia" enfrenta dificuldades para absorver a matéria-prima disponível na região, já que o município de Benjamin Constant possui ótimo potencial agrícola, como mostra a Tabela 4.

Tabela 4

Produção de Fruticultura no município de Benjamin Constant no ano de 2016.

\begin{tabular}{cccc}
\hline Matéria-Prima & $\begin{array}{c}\text { Produção Assistida } \\
(\mathbf{K g})\end{array}$ & $\begin{array}{c}\text { Produção Não Assistida } \\
(\mathbf{K g})\end{array}$ & Total (Kg) \\
\hline Açaí & 3.6000 & 294.000 & $330.000,00$ \\
Abacaxi & 277.200 & 351.000 & $628.200,00$
\end{tabular}


Estudo de Caso: Impacto dos Custos Logísticos em Agroindústria de Polpas de Frutas no Município de Benjamin Constant - Amazonas

\begin{tabular}{cccc}
\hline Matéria-Prima & $\begin{array}{c}\text { Produção Assistida } \\
(\mathbf{K g})\end{array}$ & $\begin{array}{c}\text { Produção Não Assistida } \\
(\mathbf{K g})\end{array}$ & Total (Kg) \\
\hline Camu-Camu & 0 & 21.000 & $21.000,00$ \\
Cupuaçu & 68.400 & 75.600 & $144.000,00$ \\
Total & $\mathbf{3 8 1 . 6 0 0}$ & $\mathbf{7 4 1 . 6 0 0}$ & $\mathbf{1 . 1 2 3 . 2 0 0 , 0 0}$ \\
\hline
\end{tabular}

Nota. Unidade Local de Benjamin Constant/IDAM, 2016.

\subsection{Níveis de Estoques}

Para a determinação dos níveis de estoque da empresa "Polpas da Amazônia" aplicou-se o método de Sistema Máximo-Mínimo, que segundo Pozo (2010) é aquele que se utiliza do enfoque da dimensão do lote econômico para manutenção de níveis de estoque satisfatórios. Foi observado que a fábrica estabelece uma política rigorosa de Tempo de Reposição (TR) de 02 dias entre a colheita e entrega da matéria-prima, obtendo-se um desvio padrão $(\delta)$ do fornecimento diário de matéria-prima no período analisado (três meses) de \pm 1.652 quilos. Definiu-se como grau de atendimento de $95 \%(\mathrm{k}=1,645)$ para este caso específico; com isto, calculou-se o Estoque de Segurança (ES) da empresa como apresentado na Eq. 1. Sabendo-se que o Consumo Médio (C) diário de matéria-prima é de aproximadamente 2.000 quilos, calculou-se o Ponto de Reposição (PR) como apresentado na Eq. 2.

$$
\begin{aligned}
& \mathrm{ES}=\mathrm{k}^{*} \sqrt{\mathrm{TR}} * \delta=4.000 \mathrm{~kg} \\
& \mathrm{PR}=\left(\mathrm{C}^{*} \mathrm{TR}\right)+\mathrm{ES}=8.000 \mathrm{~kg}
\end{aligned}
$$

Já o Estoque Máximo ( $\left.E_{\text {máx }}\right)$ pode ser definido como a soma entre ES e o Lote de Compras (LC). Estabelecendo que LC=2*(ES) tem-se $\mathrm{E}_{\text {máx }}$, conforme a Eq. 3.

$$
\mathrm{E}_{\text {máx }}=\mathrm{ES}+\mathrm{LC}=3 *(\mathrm{ES})=12.000 \mathrm{~kg}
$$

Com base nas informações obtidas pode-se definir o sistema de controle de estoques, conforme apresentado na Figura 7.

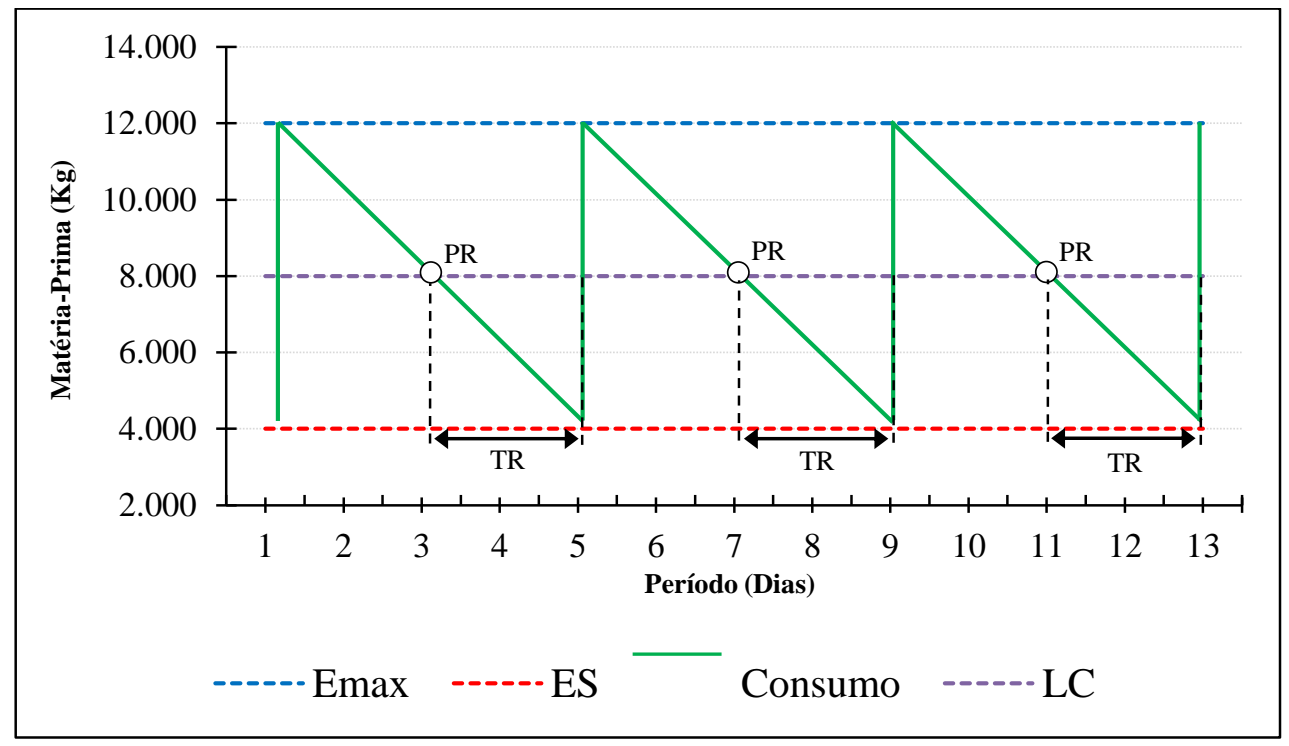

Figura 7. Sistema de Controle de Estoques da empresa "Polpas da Amazônia" Fonte: Autor (2016). 
Estudo de Caso: Impacto dos Custos Logísticos em Agroindústria de Polpas de Frutas no Município de Benjamin Constant - Amazonas

\subsection{Análise de Pareto}

Sabendo-se que a região estudada apresenta alguns produtos com maior demanda em relação aos demais, tem-se na Análise de Pareto uma técnica estatística ideal para identificar quais das matérias-primas utilizadas têm maior contribuição no faturamento ou que tem maior fluxo de movimentação (Carpinetti, 2010).

No caso específico do açaí, sabe-se que este produto há alguns anos vem aumentando seu mercado nacional e internacional, com uma demanda crescente atraindo cada vez mais novos investidores. Entretanto, sua produção local é na sua maioria oriunda de atividade extrativista, o que dificulta as previsões de fornecimento, tanto pela logística quanto sazonalidade.

E mesmo os produtos que são cultivados, como abacaxi, maracujá, dentre outros; sua viabilidade depende também dos custos logísticos, pela falta de infraestrutura necessária para sua entrega na fábrica.

A Tabela 4 mostra o rendimento da matéria-prima processada pela "Polpas da Amazônia", demonstrando que produtos como o abacaxi e camu-camu apresentam melhores resultados.

Tabela 4

Rendimento da matéria-prima processada no período de 2013 a 2015.

\begin{tabular}{cccc}
\hline Item & Matéria-prima $(\mathbf{K g})$ & Rendimento & Polpa $(\mathbf{K g})$ \\
\hline Açaí & $337.567,81$ & $50 \%$ & $168.783,90$ \\
Abacaxi & $130.693,95$ & $60 \%$ & $78.416,37$ \\
Camu-camu & $33.469,37$ & $60 \%$ & $20.081,62$ \\
Cupuaçu & $31.158,59$ & $55 \%$ & $17.137,22$ \\
Buriti & $25.194,05$ & $50 \%$ & $12.597,03$ \\
Total & $\mathbf{5 5 8 . 0 8 3 , 7 7}$ & & $\mathbf{2 9 7 . 0 1 6 , 1 4}$
\end{tabular}

Nota. Autor (2016).

Entretanto, quando se aplica a Análise de Pareto (Figura 8), verifica-se que o açaí demonstra enorme vantagem pela quantidade de oferta de matéria-prima. Sendo assim, pode-se classificar os produtos da empresa "Polpas da Amazônia" da seguinte forma:

- Classe A: o açaí é o principal produto em estoque e de alta prioridade, $20 \%$ desta matéria-prima corresponde mais de $80 \%$ da produção.

- Classe B: o abacaxi e camu-camu ainda são relevantes, $40 \%$ desta matéria-prima corresponde a pouco mais de $15 \%$ da produção.

- Classe C: o cupuaçu e buriti tem baixa prioridade, $40 \%$ desta matéria-prima corresponde a pouco mais de $5 \%$ da produção. 
Estudo de Caso: Impacto dos Custos Logísticos em Agroindústria de Polpas de Frutas no Município de Benjamin Constant - Amazonas

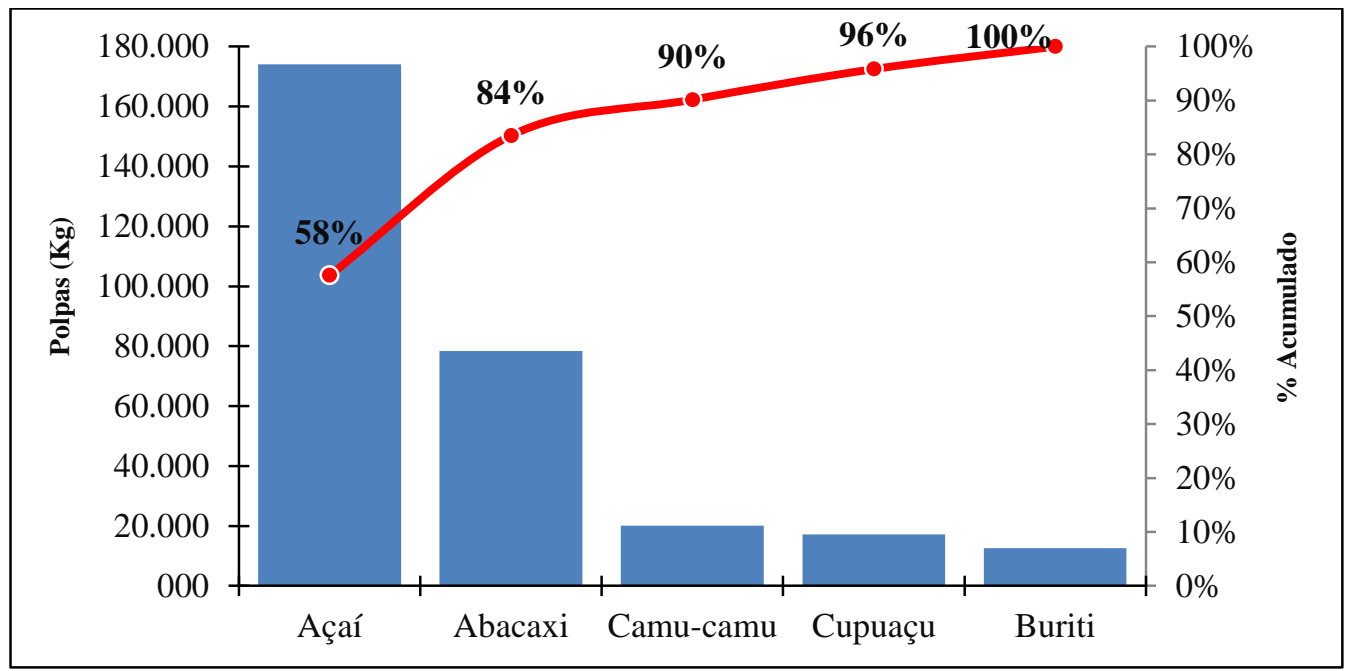

Figura 8. Análise de Pareto da Quantidade de Polpa Produzida no Período de 2013 a 2015.

Fonte: Autor (2016).

Com isso, observou-se uma tendência em concentrar esforços e recursos no processamento do produto principal (açaí) acarretando na queda na produção dos demais produtos no decorrer dos anos, de acordo com a Figura 9.

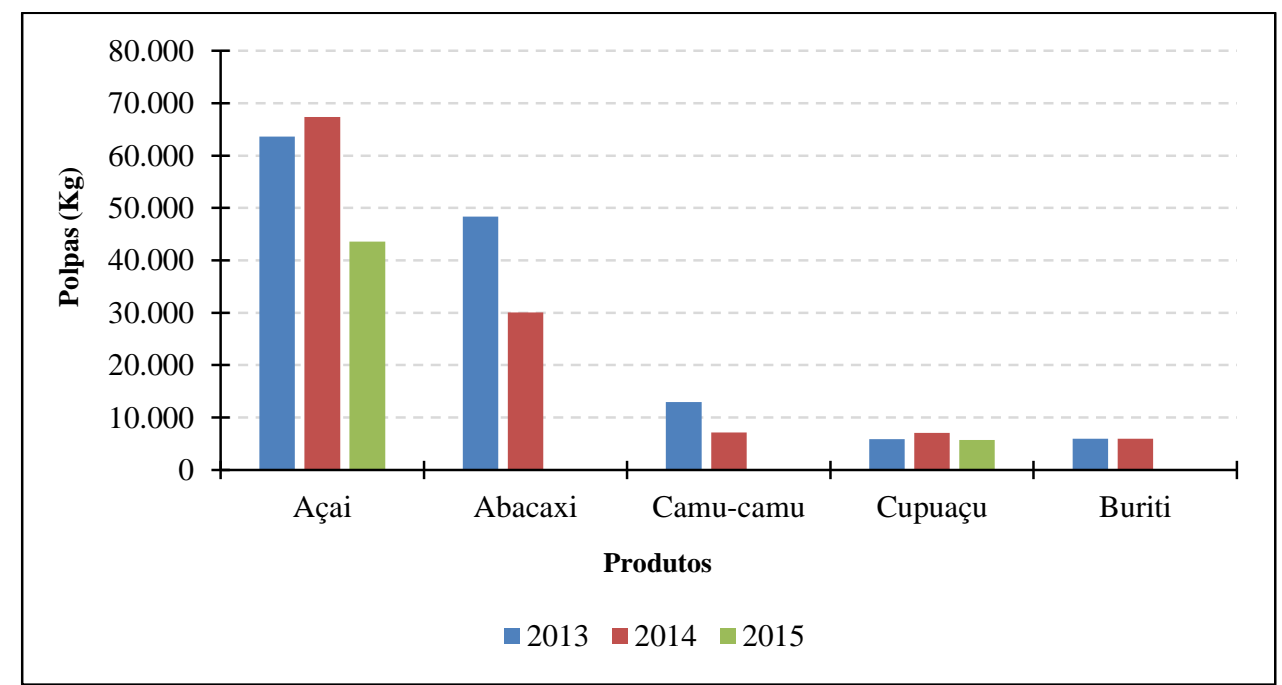

Figura 9. Produção de Polpas por Produto no período de 2013 - 2015.

Fonte: Autor (2016).

O controle da produção mensal é essencial para o desenvolvimento de todas as etapas da fábrica, sendo que a parte da manutenção da informação é essencial para o correto planejamento e controle logístico, principalmente quando se trata de manutenção de estoque.

É necessário que se mantenha uma base de dados com informações importantes, como por exemplo, localização dos clientes, volume de vendas, padrões de entregas, a fim de sustentar a integração entre as atividades primárias e de apoio.

A gestão de estoques é primordial para a redução de custos das empresas, sendo ferramenta vital na definição de estratégias empresariais competitivas, ela visa reestruturar os procedimentos operacionais de forma a capitalizar todos os esforços com o manejo dos produtos. 
Estudo de Caso: Impacto dos Custos Logísticos em Agroindústria de Polpas de Frutas no Município de Benjamin Constant - Amazonas

\section{ANÁLISE DOS CUSTOS LOGÍSTICOS}

Foram diversos os problemas apontados referentes aos impactos logísticos. Dentre eles, o mais grave é a falta de infraestrutura para o transporte, embora não reconhecido pela gestão atual da fábrica. Sabendo que o manuseio normal já produz, inevitavelmente, alguns danos, o manuseio descuidado rapidamente conduz a problemas sérios e irreparáveis, com por exemplo perda de qualidade no produto final.

Para Freires apud (Souza, Schnorr, \& Ferreira, 2013), os custos logísticos são aqueles relacionados às atividades de planejar, implantar e controlar todos os materiais e serviços de entrada, como também os materiais em processo e os produtos ou serviços de saída, desde o ponto de origem (fornecedor) até o ponto de consumo (cliente final).

Para análise dos custos logísticos, optou-se pelo método de Custeio Baseado em Atividade (Acticity Based Costing - ABC), recomendado para este tipo de análise, segundo Laidens, Teles \& Müller (2007), já que trabalhou-se basicamente com custos indiretos de serviços, normalmente associados a clientes, produtos e pedidos.

No processo de transporte de matéria-prima estudado, desconsiderou-se os custos de estoque e armazenagem, que são praticamente nulos, até mesmo pelo curto prazo entre a colheita e entrega da fruta na fábrica. É público e notório que a estrutura de armazenagem nacional é inadequada, principalmente dentro das propriedades rurais, que praticamente obriga grande parte dos produtores a escoarem sua produção logo após a colheita, num período em que os preços são relativamente baixos e o custo com fretes e transporte estão mais altos (Kussano \& Batalha, 2012).

Neste caso, observou-se que os custos de transporte da matéria-prima ultrapassam $30 \%$ da receita dos fornecedores como mostra a Figura 10, confirmando que a infraestrutura precária do município decorre em altos custos logísticos, que inevitavelmente são repassados ao consumidor final, haja vista que será necessário pagar bem mais pela aquisição de matériaprima.

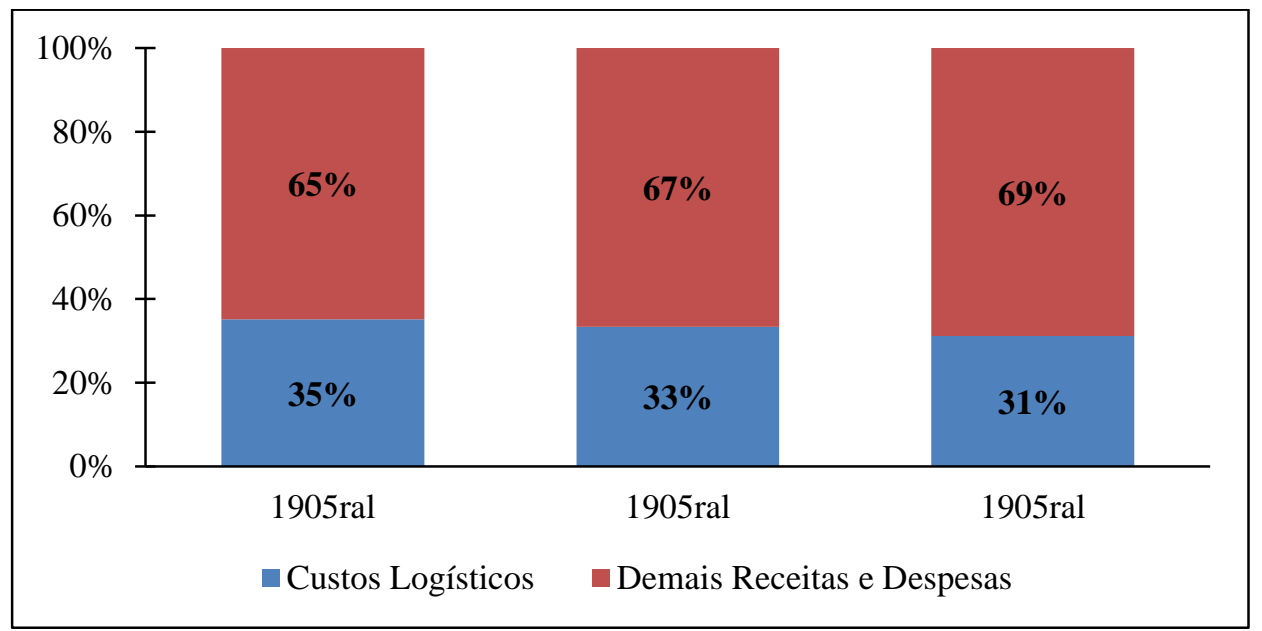

Figura 10. Impacto dos Custos Logísticos no Transporte de Matéria-Prima. Fonte: Autor (2016). 
Estudo de Caso: Impacto dos Custos Logísticos em Agroindústria de Polpas de Frutas no Município de Benjamin Constant - Amazonas

O Custo Logístico Total da (CLT) da fábrica "Polpas da Amazônia" pode ser obtido pela somatória de três itens: custo de armazenagem, custos de estoques e custo de transporte (POZO, 2010). A Figura 11 mostra que os custos com transporte representam em média 51\% do total dos custos logísticos, sendo estes valores bem superiores a tendência nacional onde segundo Gutierrez apud Ferreira e Alves (2016), esse tipo de custo consome 30\% dos custos logísticos das empresas.

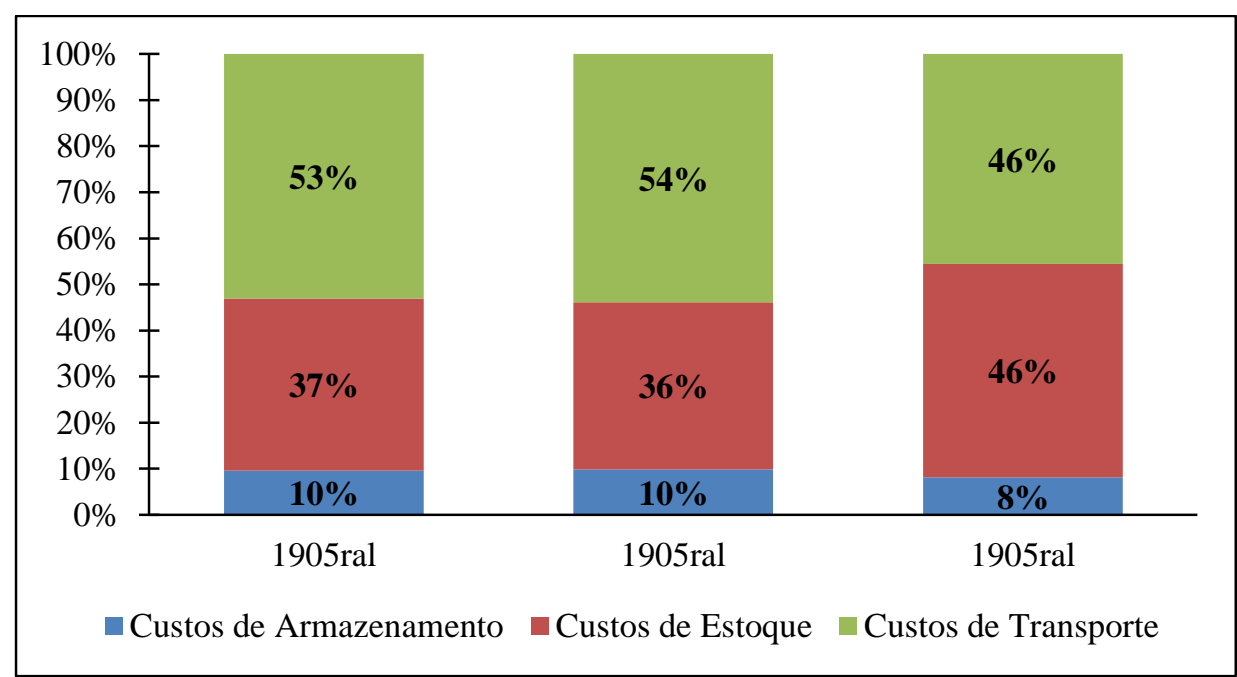

Figura 11. Custo Logístico Total da fábrica "Polpas da Amazônia". Fonte: Autor, 2016.

Numa análise geral, o custo logístico total representa em média $11 \%$ da receita como mostram os dados da Figura 12. Esses valores são próximos aos praticados nacionalmente. Isso se deve principalmente pela utilização do transporte hidroviário para a distribuição dos produtos. Inclusive, a distribuição de produtos por esse modal representa um ótimo negócio para os barcos que realizam o serviço, pois o fluxo de mercadorias dessa região com destinação à Manaus é bastante reduzido.

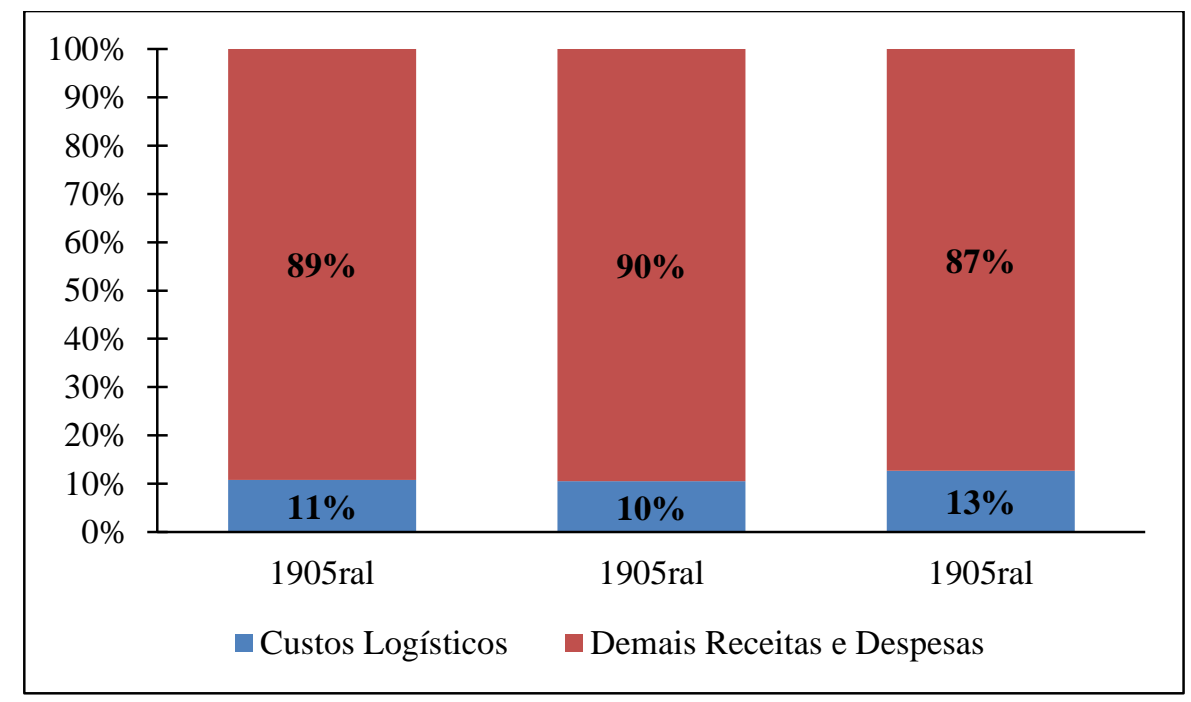

Figura 12. Impacto dos custos logísticos no processo.

Fonte: Autor, 2016. 
Estudo de Caso: Impacto dos Custos Logísticos em Agroindústria de Polpas de Frutas no Município de Benjamin Constant - Amazonas

O efeito negativo dos custos logísticos pode afetar diretamente atividade logística, por isso o controle efetivo e eficaz diante dos resultados não pode ser negligenciado. As implicações da atividade logística são diversas e podem afetar ao longo da cadeia de suprimentos.

No caso das atividades agroindustriais, a perecibilidade da matéria-prima potencializa a função logística para além do enfoque funcional de transporte, armazenagem e distribuição, para também assegurar a qualidade do produto final, ou seja, um processo de controle efetivo deste o fornecimento à comercialização (Souza et al., 2013).

\section{GESTÃO DA CADEIA DE SUPRIMENTOS}

Para obter sucesso e atingir vantagem competitiva, as organizações precisam ter forte competitividade, que é conquistada reduzindo-se os custos e agregando valor ao produto (Pozo, 2010). Um ferramenta utilizada para se atingir esses objetivos é o gerenciamento da cadeia de suprimentos (Supply Chain Management - SCM), definida por Simchi-Levi et al., (2010) como o conjunto de abordagens utilizadas para integrar todos os agentes do sistema logístico, de forma que os produtos sejam produzidos e distribuídos na quantidade certa, para o local certo e no tempo certo, de forma a minimizar os custos ao mesmo tempo que se atinge um nível de serviço desejado.

Segundo Martins e Alt (2009) o sucesso do SCM depende do grau de integração e comprometimento entre os agentes participantes do sistema logístico, do fornecedor ao cliente, que, como parceiros, podem diminuem os custos ao longo da cadeia (entre $10 \%$ e $30 \%$ ) e tempo médio de estocagem (cerca de 50\%). Segundo os autores o SCM deve abranger níveis distintos de planejamento e seus respectivos horizontes, sendo eles: Estratégico, Tático, Operacional e Transacional.

Com isto, pode-se indicar um plano para aperfeiçoamento da Gestão da Cadeia de Suprimentos, aplicável ao ambiente organizacional da fábrica "Polpas da Amazônia" como mostra a Tabela 5. 
Estudo de Caso: Impacto dos Custos Logísticos em Agroindústria de Polpas de Frutas no Município de Benjamin Constant - Amazonas

Tabela 5

Plano para Aperfeiçoamento da Gestão da Cadeia de Suprimentos.

\begin{tabular}{|c|c|c|c|c|}
\hline Nível & Plano & Ação & Objetivos & Prazo \\
\hline \multirow{4}{*}{ Estratégico } & \multirow[b]{3}{*}{ Mercado } & $\begin{array}{l}\text { Integrar } \\
\text { fornecedores, } \\
\text { fábrica } \\
\text { consumidores }\end{array}$ & $\begin{array}{l}\text { Conhecer melhor os } \\
\text { participantes do processo, } \\
\text { partilhando das dificuldades } \\
\text { enfrentadas por ambas as partes } \\
\text { e propor soluções. }\end{array}$ & Médio/Longo \\
\hline & & $\begin{array}{l}\text { Pesquisar } \\
\text { mercados } \\
\text { alternativos }\end{array}$ & $\begin{array}{l}\text { Procurar mercados em potencial } \\
\text { antecipando-se a cenários de } \\
\text { aumento da produção. }\end{array}$ & Longo \\
\hline & & $\begin{array}{l}\text { Vender } \\
\text { mercado } \\
\text { doméstico }\end{array}$ & $\begin{array}{l}\text { Analisar econômica } \\
\text { financeiramente } \\
\text { comercialização dos produtos } \\
\text { nos municípios da região, } \\
\text { reduzindo com isso os custos de } \\
\text { distribuição. }\end{array}$ & Médio/Longo \\
\hline & Aprendizagem & $\begin{array}{l}\text { Firmar parcerias } \\
\text { de apoio técnico e } \\
\text { científico }\end{array}$ & $\begin{array}{l}\text { Manter contato com instituições } \\
\text { públicas que possam contribuir } \\
\text { com a fábrica através de novas } \\
\text { técnicas e estudos que } \\
\text { aprimorem a sua função } \\
\text { logística. }\end{array}$ & Médio/Longo \\
\hline \multirow{3}{*}{ Tático } & \multirow{3}{*}{$\begin{array}{l}\text { Fornecimento } \\
\text { e Distribuição }\end{array}$} & $\begin{array}{l}\text { Racionalizar de } \\
\text { Remessas de } \\
\text { matéria-prima e } \\
\text { produtos }\end{array}$ & $\begin{array}{l}\text { Evitar que produtos e/ou } \\
\text { matéria-prima que possam ser } \\
\text { transportados em uma única } \\
\text { remessa, tenham que ser } \\
\text { transportados mais de uma vez. }\end{array}$ & Curto/Médio \\
\hline & & $\begin{array}{l}\text { Melhorar o modal } \\
\text { rodoviário }\end{array}$ & $\begin{array}{l}\text { Solicitar ações governamentais } \\
\text { para recuperação das rodovias e } \\
\text { estradas, e preferencialmente, } \\
\text { sua pavimentação. }\end{array}$ & Médio/Longo \\
\hline & & $\begin{array}{l}\text { Aumentar a oferta } \\
\text { de matéria-prima } \\
\text { oriunda de } \\
\text { fruticultura }\end{array}$ & $\begin{array}{l}\text { Este tipo de matéria-prima } \\
\text { possui características que } \\
\text { garantem maior previsibilidade, } \\
\text { possibilitando-se firmar grandes } \\
\text { contratos de fornecimento e } \\
\text { distribuição, com a } \\
\text { possibilidade de descontos. }\end{array}$ & Médio \\
\hline \multirow[t]{2}{*}{ Operacional } & \multirow[t]{2}{*}{ Produção } & $\begin{array}{l}\text { Aumentar a } \\
\text { participação dos } \\
\text { produtos de classe } \\
\text { B }\end{array}$ & $\begin{array}{l}\text { Garantir que a matéria-prima } \\
\text { disponível chegue à fábrica, } \\
\text { aumentando sua produção, e } \\
\text { reduzindo a dependência } \\
\text { econômica do principal produto } \\
\text { (açaí). }\end{array}$ & Médio/Longo \\
\hline & & $\begin{array}{l}\text { Executar } \\
\text { manutenção } \\
\text { preventiva das } \\
\text { máquinas } \\
\text { equipamentos }\end{array}$ & 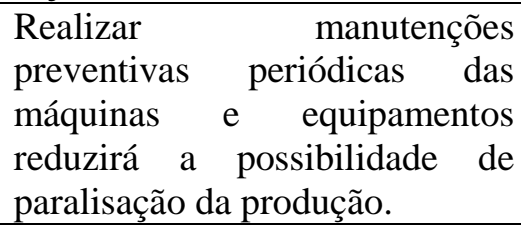 & Médio \\
\hline Transacional & $\begin{array}{l}\text { Tecnologia de } \\
\text { Informação }\end{array}$ & $\begin{array}{l}\text { Adquirir } r \text { de } \\
\text { Sistema de Gestão } \\
\text { com o módulo } \\
\text { logístico }\end{array}$ & $\begin{array}{l}\text { Fornecer informações precisas } \\
\text { para o gerenciamento da Cadeia } \\
\text { de Suprimentos. }\end{array}$ & Curto \\
\hline
\end{tabular}


Estudo de Caso: Impacto dos Custos Logísticos em Agroindústria de Polpas de Frutas no Município de Benjamin Constant - Amazonas

Nota. Autor, 2016.

De acordo com Marques e Alcântara (2004) o conceito de cadeia de suprimento visa à eficiência de todos os agentes envolvidos, através da sincronização de todas as atividades de produção, de forma a reduzir os custos, minimizar os ciclos e maximizar o valor percebido pelo cliente final, por meio do rompimento das barreiras entre departamentos e áreas.

Com isto, tem-se nesse plano de aperfeiçoamento uma alternativa para tentar minimizar os custos financeiros e operacionais da fábrica "Polpas da Amazônia", fortalecendo a função logística e com isso agregar-se valor ao produto final, contribuindo significativamente para o desenvolvimento da atividade industrial local.

\section{CONCLUSÕES}

Com este trabalho foi possível entender como os custos logísticos da região interferem nos processos industriais realizados fábrica "Polpas da Amazônia", instalada no município de Benjamin Constant - Amazonas. Além disso, traçou-se o ambiente organizacional desta agroindústria de polpas de frutas, e sua contribuição para a economia local.

Constatou-se que estes problemas logísticos tornam a Cadeia de Suprimentos ineficaz no fornecimento de matéria-prima, pois não se absorve quantidades suficientes para o pleno funcionamento da fábrica estuda. Isso se deve em grande parte pelos custos de transporte, que acarretam impactos financeiros e operacionais. Na parte financeira, os custos com transporte dos fornecedores elevam o valor pago pela matéria-prima, e consequentemente, aumento no preço do produto final. Na parte operacional, os fornecedores que precisam enfrentar longas distâncias, estradas e rodovias precárias deixam de oferecer a matéria-prima dado ao valor custo/benefício da operação.

Evidencia-se que os custos logísticos de distribuição de produtos estão próximos aos índices nacionais, dado principalmente pelo uso do modal hidroviário, que se apresenta com preços acessíveis de frete dado a baixa circulação de mercadorias na rota das embarcações que realizam esse serviço. Isso possibilita a participação da empresa em mercados competitivos e com consumidores de maior poder aquisitivo, absorvendo toda a produção da fábrica, reduzindo custos de estoque e armazenamento.

Como a "Polpas da Amazônia" foi instalada com propósitos econômicos e sociais, a integração com os fornecedores faz-se necessária, sendo os mesmos também parte integrante das comunidades no entorno das atividades desenvolvidas, criando-se uma relação de interdependência, onde a fábrica precisa dos seus fornecedores para garantir a matéria-prima necessária, estes por sua vez, precisam daquela para garantir uma melhoria de renda. O grau de envolvimento dessa relação deve ser intensificado, pois acarretará em melhorias para a cadeia de suprimentos.

Através deste trabalho, pôde-se identificar e analisar as potencialidades e ameaças à cadeia de suprimentos da fábrica "Polpas da Amazônia" na região estudada, porém, trouxe à tona uma discussão mais ampla acerca das dificuldades para se manter uma atividade industrial no município de Benjamin Constant, Amazonas, sabendo que estes vão muito além da logística empresarial. 
Estudo de Caso: Impacto dos Custos Logísticos em Agroindústria de Polpas de Frutas no Município de Benjamin Constant - Amazonas

\section{REFERÊNCIAS}

Acevedo, C. R., \& Nohara, J. J. (2007). Monografia no curso de administração: guia completo de conteúdo e forma: inclui normas atualizadas da ABNT, TCC, TGI, trabalhos de estágio, dissertações, teses. ( $3^{\mathrm{a}}$ ed.). São Paulo: Atlas.

Ballou, R. H. (2006). Gerenciamento da Cadeia de Suprimentos/Logística Empresarial. (5 ed.) Porto Alegre: Bookman.

Ballou, R. H. (2010). Logística Empresarial: Transportes, Administração de Materiais e Distribuição Física. São Paulo: Atlas.

Ballou, Ronald H. Logística Empresarial: Transportes, Administração de Materiais e Distribuição Física. 1. ed. São Paulo : Atlas, 2012.

Barbosa, G. W. R. (2011). Gestão Estratégica de Matéria Prima para Agroindústria. Dissertação (Mestrado Profissional em Desenvolvimento de Tecnologia). LACTEC: Curitiba. Disponível Recuperado de: http://sistemas.lactec.org.br/mestrado/dissertacoes/arquivos/GlennBarbosa.pdf.

Carpinetti, L. C. R. (2010). Gestão da Qualidade: princípios e conceitos. São Paulo: Atlas.

Christopher, M. (2009). Logística e gerenciamento da cadeia de suprimentos: Criando redes que agregam valor. ( $2^{\mathrm{a}}$ ed.). São Paulo: Cengage Learning.

Faria, C. A., \& Costa, G. F. M. (2007). Gestão de Custos Logísticos. São Paulo: Atlas.

Ferreira, K. A., \& Alves, M. R. P. A. (2016). Logística e troca eletrônica de informação em empresas automobilísticas e alimentícias. (Vol. 15). Recuperado de: http://www.scielo.br/scielo.php?script=sci_arttext\&pid=S0103$65132005000300012 \& \operatorname{lng}=$ en $\&$ nrm=iso\&tlng=pt.

Grim, J. H., Hofstetter, J. S., \& Sarkis, J. (2014). Fatores Críticos para a Gestão de SubFornecedores: Uma Perspectiva Sustentável das Cadeias de Abastecimento de Alimentos. Int. J. Production Economics.

Guereschi, Jonathan Soares. Logística De Transporte: A Importância Dos Custos Logísticos Ajm Transporte Ltda - LINS - SP. Lins, 2012.

Jack, G. A. J. van der Vorst; Da Silva, C. A.; \& Trienekens, J. H. (2007). Agroindustrial Supply. Gerenciamento de Cadeias: Conceitos e Aplicações. Organização das Nações Unidas para a Alimentação e a Agricultura. Roma.

Karsaklian, E. (2000). Comportamento do consumidor. São Paulo: Atlas.

Kussano, M. R., Batalha, M. O. (2012). Custos Logísticos Agroindustriais: Avaliação do Escoamento da Soja em grão do Mato Grosso para o Mercado Externo. Gestão \& Produção. $\quad$ v. $19 . \quad$ Recuperado de: http://www.scielo.br/scielo.php?script=sci_arttext\&pid=S0104-530X2012000300013.

Marques, E. F., \& Alcântara, R. L. C. (2004). O Uso da Ferramenta Gerenciamento por Categoria na Gestão da Cadeia de Suprimentos: Um Estudo Multicaso. Gestão \& Produção. v. 11. Recuperado de: http://www.scielo.br/pdf/gp/v11n2/a02v11n2.pdf. 
Estudo de Caso: Impacto dos Custos Logísticos em Agroindústria de Polpas de Frutas no Município de Benjamin Constant - Amazonas

Martins, P. G., \& ALT, P. R. C. (2009). Administração de Materiais e Recursos Patrimoniais. ( $3^{\mathrm{a}}$ ed.). São Paulo: Saraiva.

Mello, C. H. P., \& Turrioni, J. B. (2012). Metodologia de pesquisa em engenharia de produção: estratégias, métodos e técnicas para condução de pesquisas quantitativas $e$ qualitativas. Universidade Federal de Itajubá. Programa de Pós-graduação em Engenharia de Produção. Recuperado de: http://www.carlosmello.unifei.edu.br/Disciplinas/Mestrado/PCM-10/ApostilaMestrado/Apostila_Metodologia_Completa_2012.pdf.

Nogueira. C. L., \& Machado, W. V. (2004). Logística: um Desafio à Competitividade do Polo Industrial de Manaus. XXIV Encontro Nac. de Eng. de Produção. Florianópolis. Recuperado http://www.abepro.org.br/biblioteca/enegep2004_enegep0112_1302.pdf.

de:

Oliva, J. A. B. (2008). Cenário Atual do Transporte Hidroviário Brasileiro. $5^{\circ}$ Seminário Internacional em Logística Agroindustrial. Piracicaba. Recuperado de: http://web.antaq.gov.br/Portal/pdf/palestras/Mar0817PiracicabaAlexOliva.pdf.

Passos, L. H. S. (2013). A logística de transportes na Amazônia Ocidental: desafios, limitações e importância para o desenvolvimento do Estado de Roraima. Revista de Administração de Roraima. Boa Vista. Recuperado de: https://revista.ufrr.br/adminrr/article/download/1723/1172.

Pozo, H. (2010). Administração de Recursos Materiais e Patrimoniais: uma abordagem logística. (6 ${ }^{\mathrm{a}}$ ed.). São Paulo: Atlas.

Sakai, J. (2011). A importância da logística para a competitividade das empresas: Estudo de caso na indústria do Polo de Camaçari. Dissertação (Mestrado Engenharia). Salvador. Recuperado

de: http://www.adm.ufba.br/sites/default/files/publicacao/arquivo/sasaki_dissertacao_final .pdf.

Segre, G. (Ed.). (2014). Manual Prático de Comércio Exterior. (4 ed.). São Paulo: Atlas.

Silva, J. N. da. (2012). Prática Logística na Pequena e Média Empresa como Fator Contribuinte para a Manutenção do Negócio. Dissertação (Mestrado em Administração e Desenvolvimento Empresarial). Universidade Estácio de Sá, Rio de Janeiro. Recuperado de: http://portal.estacio.br/media/2706/juarez_nuno_.pdf.

Silva, A. L., FISCHMANN, A. A. (1999). Impacto da Tecnologia de Informação no Supply Chain Management: Um Estudo Multicaso Sobre a Adoção de EDI entre Varejo e Indústria Agroalimentar. $\quad$ v. $6 . \quad$ Recuperado de: http://www.scielo.br/pdf/gp/v6n3/a06v6n3.pdf.

Simchi-Levi, D., Kaminsky, P., \& Simchi-Levi, E. (2010). Cadeia de Suprimentos Projeto e Gestão: Conceitos, Estratégias e Estudos de Caso. (3 ${ }^{\mathrm{a}} \mathrm{ed}$.). Porto Alegre: Bookman.

Slack, N., Chambers, S., \& Johnston, R. (2009). Administração da Produção. São Paulo: Atlas.

Souza, M. A., Schnorr, C., Ferreira, F. B. (2013) Práticas de gestão de custos logísticos: Estudo de caso de uma empresa do setor alimentício. Revista Contemporânea de Contabilidade. Recuperado de: http://www.redalyc.org/articulo.oa?id=76226206002.

UFAMBR, Manaus, v. 1, n.2, art. 3, pp. 42-66, julho-dezembro, 2019 http://www.periodicos.ufam.edu.br/ufambr 
Estudo de Caso: Impacto dos Custos Logísticos em Agroindústria de Polpas de Frutas no Município de Benjamin Constant - Amazonas

Souza, M. A., Zwirtes, A., Rodniski, C. M., Borghetti, J. C. (2013). Gestão de Custos Logísticos: um estudo das práticas utilizadas por uma Cooperativa Agroindustrial Catarinense. Recuperado de: http://seer.ufrgs.br/index.php/ConTexto/article/view/27117/pdf.

Souza, P. A. R. de, Bentes, C. T., Gonçalves, H. G., Durães, R. M., \& Cursino, R. S. (2011). O Serviço de Logística de Distribuição do Interior do Amazonas. Revista Eletrônica de Administração. Recuperado de: http://periodicos.unifacef.com.br/index.php/rea/article/viewFile/492/465.

Vieira, Thaisa R., Vieira, Thalita R. (2014). A Engenharia de Tráfego na Logística de Transporte: Um Estudo de Caso em uma Concessionária de Rodovias na Região Noroeste do Estado de São Paulo. Curso Superior de Tecnologia em Logística. Lins. Recuperado de: http://www.fateclins.edu.br/site/trabalhoGraduacao/M4yKQrFLQ6Kf6N6LgRMww4 w4i59zuNW14lHlrgL5Vx.pdf.

Gianesi, I. G. N., Biazzi, J. L. (2011). Gestão estratégica dos estoques. Revista de Administração. USP: São Paulo. Recuperado de: http://200.232.30.99/download.asp?file=v4603290.pdf.

Laidens, G., Teles, C. D., Müller, C. J. (2007) Avaliação dos custos logísticos em empresas do setor alimentício. Estudos tecnológicos. Recuperado de: http://www.revistas.unisinos.br/index.php/estudos_tecnologicos/article/view/5732/293 1. 